\title{
Murine models of bone Sarcomas
}

Camille Jacques $^{1}$, Nathalie Renema ${ }^{1}$, Benjamin Ory ${ }^{1}$, Carl R. Walkley ${ }^{2}$, Agi E. Grigoriadis ${ }^{3}$, Dominique Heymann ${ }^{4,5}$

Running head: Murine models of bone sarcomas

${ }^{1}$ INSERM, U1238, University of Nantes, FR

2. St. Vincent's Institute of Medical Research, Department of Medicine, St. Vincent's Hospital, University of Melbourne, Australia

3. Centre for Craniofacial and Regenerative Biology, King's College London Guy's Hospital, London, UK

${ }^{4}$ University of Sheffield, Medical School, Dept of Oncology and Metabolism. INSERM, European Associated laboratory «Sarcoma Research Unit». Beech Hill Road, S10 2RX Sheffield, UK

5 Institut de Cancérologie de l'Ouest, INSERM, U1232, University of Nantes, «Tumour Heterogeneity and Precision Medicine », Blvd Jacques Monod, 44805 Saint-Herblain cedex, France

\section{Corresponding author :}

Prof. Dominique Heymann

Institut de Cancérologie de l'Ouest, INSERM, U1232, University of Nantes, "Tumour Heterogeneity and Precision Medicine », Blvd Jacques Monod, 44805 Saint-Herblain cedex, FR

Email: dominique.heymann@univ-nantes.fr 


\begin{abstract}
This chapter describes the procedures for inducing bone sarcoma in mice. Two models based on inoculation of cancer cells in paraosseous and intraosseous site will be described. In addition to providing technical aspects of anaesthesia and surgical options, key information of cell preparation and post-operative follow-up will be discussed.
\end{abstract}

Key words: Bone sarcoma, osteosarcoma, Ewing sarcoma, chondrosarcoma, cell-injection, murine pre-clinical models, genetically-engineered mouse models. 


\section{Introduction}

The two most common methods used to induce bone sarcoma in mice involves the injection of a concentrated suspension of murine (allograft) or human (xenograft) tumour cells, either in close contact to the bone or into the bone medullary cavity (such as into the femur or tibia $)^{1,2}$. The choice of model depends on the aim of the study and the expected investigation strategies. For instance, models utilizing injection in orthotopic sites of established cell lines from the respective tumour types are readily induced compared to the genetically-engineered ${ }^{3-6}$ or patient-derived xenograft $(\mathrm{PDX})^{7-10}$ models. These models mimic human disease progression including local tumour growth with high recurrence after resection and the formation of distant metastases in some models. Orthotopic tumour models are suited to screen the efficacy of new drugs and genetically modified cancer cells can be used for mechanistic investigations. However, these models have disadvantages, as the cell lines used may not possess the genetic heterogeneity or the histological features of the human tumours. In contrast, genetically engineered models characterized by a spontaneous tumour development mimic the natural history of the disease with a host microenvironment that resembles the tumour micro-environment in human. PDX models allow the preservation of the cellular heterogeneity of the initial tumour fragments. These models are associated with the "spontaneous" development of tumours that mimics the natural development of bone sarcomas and their heterogeneity can more closely approximate the in vivo behavior of the human disease. These models are relatively easy to utilise for in vivo imaging, such as microCT or microPET. Except for Ewing sarcoma, for which no high fidelity geneticallyengineered mouse models have currently been established ${ }^{3}$, the recent improvements both in the sequencing technology and the genetic modification field have contributed to the development of numerous genetically-engineered murine models of bone sarcomas, and a non-exhaustive list of the established models is detailed in Table 1. In the present chapter, we will describe the procedures that are frequently used to induce bone sarcoma growth in mice based on orthotopic inoculation of cancer cells. 


\section{MATERIALS}

\subsection{Cell culture reagents}

1. Culture medium [e.g. Dulbecco's modified Essential medium (DMEM), Roswell Park Memorial Institute medium (RPMI)-1640 according to the cell line used].

2. Glutamine (2mM).

3. Fetal Bovine Serum (FBS).

4. $\operatorname{Tryp} \sin (0.25 \%$ solution$) /$ EDTA $(0.02 \%)$.

5. Free of calcium and magnesium Phosphate Buffered Saline (PBS, $\mathrm{pH}=7.2$ ).

6. Trypan Blue solution $0.4 \%$.

7. 4-8-week-old mice (strains depending on the model used)(Table 2)

\subsection{Equipment and surgical instruments}

1. Scalpel blades/clipper.

2. Surgical suture thread/needles.

3. Sterile Hamilton syringes/needles.

4. Antiseptic solution (i.e Betadine dermal solution, polyvidone iodine).

5. Warming mat/plate and clean recovery cage

2.3 Anaesthetic Agents and equipment : Isoflurane/oxygen-based anesthesia system, fitted with an induction chamber and individual inhalation masks for mice.

2.4 Analgesic Agent : Buprenorphine. 


\section{METHODS}

All the procedures described in this chapter must be approved and conducted in accordance with the local regulatory ethics and national regulation committees.

\subsection{Animal husbandry}

1. House animals (4-8-week-old mice: strains depending on the origin of cells used) in pathogen-free rooms maintained at constant temperature, with 12-h light/12-h dark cycles.

2. Provide free access to water and standard, pelleted commercial diet.

3. Allow animals an acclimatisation period of at least 1 week prior operating if transported from different facility.

\subsection{Cell culture}

Cell cultures should be produced in sterile environment and prepared under clean conditions (working in a flow cabinet, use of sterile media and instruments etc).

1. Bone sarcoma cells: human or animal bone sarcoma cell lines cultured in adequate medium supplemented with $10 \%$ of Fetal Bovine Serum. (see Note 1)

2. Culture the cells until approximately $80 \%$ confluence in Petri dishes or cell-culture flasks. (see Note 2)

3. Wash the cells with PBS and detach cells from the plastic surface by a five minute incubation at $37^{\circ} \mathrm{C}$ with trypsin-EDTA solution. (see Note 3 )

4. Stain cells with Trypan Blue (Dilute 1:1) and count using a Haemocytometer or an automated cell counter according to manufacturer's instructions.

5. Dilute the suspension in order to have $1-2 \times 10^{6}$ cells $/ 50 \mu \mathrm{L}$ for injection per mouse, or as the experimental conditions dictate. (see Note 4) 
6. Dilute the cells in a $0.5 \mathrm{~mL}$ micro-tube and store them on ice prior to the mice injections (see Note 5).

\subsection{Procedure of cell inoculation in mice}

The experiments described below should only be conducted with the approval of your individual Animal Ethics and Use Committee.

\subsubsection{Induction of anesthesia}

1. Place the mouse into an induction-box and carefully close the lid of the box.

2. Anesthetize the mouse by inhalation of a combination isoflurane/air $(1.5 \%, 1 \mathrm{~L} / \mathrm{min})$ and buprenorphine $(0.05 \mathrm{mg} / \mathrm{kg})$. The procedure can take several minutes depending on each individual and the number of animals placed in the induction-box. (see Note 6)

3. When the animal is anesthetized, place it on the back onto a warming pad to ensure that its body temperature remains stable for the duration of the experiment.

4. Place the tip of the nose of the mouse into an individual anesthesia mask connected with the isoflurane/air pipeline system.

5. Check the effectiveness of the anesthesia by "pinching/squeezing" the foot of the individual animal. Check for any reaction to this pressure. If the mouse reacts, wait a further minute before repeating the "pinching/squeezing" of the foot and carefully check the position of the mask on the animal nose. If needed, you can also slightly increase the isoflurane dose.

\subsubsection{Preparation of the injection site}

1. Disinfect the left hind leg (mouse on the back, head up top) with an antiseptic pad. If you are not working with a nude/hairless mouse strain, shave the leg of the animal using a scalpel blade, shaver (electric) or depilitary cream. Remove the remaining hairs from the area to inject using an alcohol pad. 
2. To properly position the leg of the mouse for the injection: Fold the left knee of the mouse in a manner that the foot lays flat on the ground of the heating plate. (Figure 1).

3. Maintain the knee of the animal into this outstretched position with your left-hand index finger and thumb and by exerting a pressure downward toward the heating plate.

4. Load the syringe with the tumour cell suspension. The cells should be transported and stored on ice from the cell culture facility to the animal housing facility. Gently homogenize the tube by vortexing it and draw the appropriate amount of cell suspension without creating any bubbles into the syringe.

\subsubsection{Operative technique for para-tibial cell injection}

1. Place the loaded syringe (fitted with a $26-28 \mathrm{G}$ needle) in your right hand and position the needle perpendicular to the tibia of the animal.

2. Using a quick and fluid motion, push it through the muscle until it touches the bone.

3. Gently scratch the periosteum of the bone (external lateral superior metaphysis) with the tip of the syringe by a light and circular motion through the bone. This step is crucial to activate the periosteum and ensure a good cellular-engraftment. (see Note 7) (Figure 2)

4. Gently inject the required volume of cell suspension in close contact to the bone. (see Note 5)

5. Always ensure a perpendicular angle, then remove the needle from the injection site and allow the animal to recover in a clean cage on a heated pad until mobile. (see Note 8)

\subsubsection{Operative technique for intra-tibial cell injection}

1. Take a sterile scalpel blade and make a 5mm midline skin-incision just below the knee joint, to expose the tibial tuberosity. 
2. Position the filled syringe (fitted with a $26-28 \mathrm{G}$ needle) in your right hand and position the needle vertically, on to the tibia of the animal.

3. Using a quick and straight motion, push it into the medullar cavity of the bone. Gently inject the required volume of cell-suspension $(5-10 \mu \mathrm{L})$ into the bone. (see Note 9)

4. In a slow and vertical movement, remove the needle from the bone. A slower motion helps to prevent the formation of venous emboli associated with the direct spreading of the tumour cells into the bloodstream. (see Note 10)

5. Close the skin with surgical suture points and allow the animal to recover in a clean age on a warming pad until mobile.

6. Once the mouse is awake, you can put it into its housing-cage.

7. Monitor the health of the animals and the tumour growth daily (see Note 11), for the entire period of the assay. Be aware of some possible side effects and to have advices to alleviate them, if applicable (see Note 12)

8. The tumour volumes $(V)$ can be calculated by measuring two perpendicular diameters using calipers, according to the following formula: $V=0.523 \times L \times(S)^{2}$ in which $L$ and $S$ are, respectively, the largest and the smallest perpendicular diameters.

9. Pain relief is recommended (e.g. buprenorphine $0.05 \mathrm{mg} / \mathrm{kg}$ ) as indicated according to the Institutional Animal Ethics and Use Committee Guidelines. Contact with your facility veterinarian or manager should be undertaken prior to initiating these experiments to discuss your specific facility and animal ethics requirements. (see Note 13) 


\section{NOTES}

1. The supplemented medium is stable for approximately four weeks at $4^{\circ} \mathrm{C}$. We do not recommend the use of antibiotic/antimitotic solutions for preparing cell suspension.

2. At the time of the injection, note the confluence level of the cells and insure that it does not exceed $80 \%$, especially for the Ewing Sarcoma cell lines. The level of confluence will affect the cells proliferative rate and their subsequent rate of proliferation in mice. Depending upon the cell lines used, a 100\% confluence level may work but could slow down the in vivo development of the tumours and needs to be determined for each cell line individually.

3. Rinsing and counting the cells in a $50 \mathrm{~mL}$ culture tube helps with obtaining a wellattached cell pellet that is easily re-suspended and accurately counted.

4. The cells should be suspended into a minimal volume (0.5 to 4 million cells in $10-50 \mu \mathrm{L}$ of PBS) to reduce the development of inflammatory reaction at the time of the injection.

5. Be sure to have enough cells to conduct the experiment, including additional samples for wastage; due to dead-space in the syringe and needle, if not using insulin syringes, and for resuspension.

6. Anesthesia can take few minutes after the beginning of the isoflurane/air diffusion, depending on the number of mice present in the induction-box. If the procedure takes more than 5 minutes, slightly increase the isoflurane flow and confirm that there is sufficient isoflurane. It is unnecessary to put the entire head of the mouse into the anesthesia-mask. Ensure that the tip of the mouse nose of the animal is into the respiratory-system. Also check that the isoflurane/air is well distributed through the mask (i.e. the isoflurane/air inlet is well opened or there are no hole in the pipelines) (not applicable if using injectable anaesthesia). 
7. Be careful of avoiding the formation of bubbles in the syringe when you draw up the cellsuspension, as it introduces variability in the volume the recipients in a group. To avoid this, be sure to draw up the liquid by starting with the plunger fully depressed into the syringe. If bubbles form, put the syringe vertically, the needle up-positioned and remove them on the top of the syringe by a finger gesture. Then, push the piston until a drop forms at the extremity of the needle (note - safety glasses should be worn).

8. During the para-tibial cell injection process, be careful to always put the needle of the syringe perpendicularly to the tibia of the animals. Cancer cells should be inoculated in close contact to the periosteum and the dispersion of the cells into the muscle along the trajectory of the needle should be avoided. These recommendations will ensure a proper bone-attached tumour engraftment instead of an unwanted intra-muscular development. In addition, be careful to remove the needle in the same axis as the one you follow to inject, as it will reduce disseminating too many cells outside the bony site. Moreover, we recommend using thin wall sterile needles (like BD Ultra-Fine Insulin $0.3 \mathrm{~mL}$ syringes (31G x $8 \mathrm{~mm}$ for example) to limit the soft tissue injury during the para-tibial injection.

9. If blood is detected in the syringe after the injection, it indicates that you have probably injected tumour cells into the bloodstream. If so, the mouse may develop lung-metastases due to intravenous injection has occurred.

10. Limit the number of animals injected with the same needle to avoid the cells sedimenting in the syringe and trying to inject with a blunt needle (i.e. 3-4 animals). To ensure that each mouse receiving the same cell number, vortex cell suspension before each injection.

11. Note that with the intra-osseous injection method, the tumour growth is slower than in the para-tibial injection, as the tumour has to invade the medullar and the cortical bone first before reaching the surrounding soft tissues and becoming observable macroscopically on the mouse limb (or palpatable) (Figure 2). These sites of injections are considered closer 
to the human pathology but are also often associated with trabecular bone destruction and an acute inflammatory process partially mediated by the development of venous emboli and the immediate dissemination of the tumour cells into the bloodstream.

12. Various imaging techniques can be used for longitudinal monitoring of bone sarcoma development from two-dimensional X-ray to three-dimensional microcomputed tomography (microCT) which allow to obtain key parameters of bone microarchitecture associated to the tumours in live animals (Figure 3). These techniques can be used for all models previously described. To study the early stage of tumour growth before palpable tumour mass, cells overexpressing firefly luciferase can be used to generate animal models. These modified cells (e.g. primary and metastastic foci) can be tracked in living animals by bioluminescent imaging and the photons emitted from modified cells can be quantified via a digital camera and advanced computer software.

13. During the course of the bone sarcoma development, several side effects may be observed. Pain must be controlled during the procedure by general anaesthesia and post procedure by analgesic administration. The most frequently described adverse events are pronounced weight loss and a progressive disuse of the tumour-bearing leg. The animal must be weighed twice weekly once evidence of tumour growth has been established and if the body weight reduces below the recommendations of the local animal facility, the experimental procedure should be stopped. In addition, if the animals show marked and persistent piloerection (raised fur; a "fluffy or dishevelled appearance"), eating/drinking difficulties for longer than $48 \mathrm{~h}$, have persistent hypothermia, enlarged lymph glands, bleeding/mucopurulent discharge from any orifice, anaemia, incontinence/diarrhoea, hind limb paralysis/weakness, tumours that prevent locomotion or have intermittent hunching and/or tremors or convulsions or disturbed breathing (e.g. lung metastases), the animal must be sacrificed immediately. 


\section{REFERENCES}

1. Odri, G.A., Dumoucel, S., Picarda, G., Battaglia, S., Lamoureux, F., Corradini, N., Rousseau, J., Tirode, F., Laud, K., Delattre, O., Gouin, F., Heymann, D., and Redini, F. (2010) Zoledronic acid as a new adjuvant therapeutic strategy for Ewing's sarcoma patients. Cancer Res. 70, 7610-7619.

2. Cherrier, B., Gouin, F., Heymann, M.F., Thiéry, J.P., Rédini, F., Heymann, D., and Duteille, F. (2005) A new experimental rat model of osteosarcoma established by intrafemoral tumor cell inoculation, useful for biology and therapy investigations. Tumour Biol. 26, 121-130.

3. Minas T.Z., Surdez, D., Javaheri, T., Tanaka, M., Howarth, M., Kang, H.J., Han, J., Han, Z.Y., Sax, B., Kream, B.E., Hong, S.H., Çelik, H., Tirode, F., Tuckermann, J., Toretsky, J.A., Kenner, L., Kovar, H., Lee, S., Sweet-Cordero, E.A., Nakamura, T., Moriggl, R., Delattre, O., and Üren, A. (2017) Combined experience of six independent laboratories attempting to create an Ewing sarcoma mouse model. Oncotarget 8,34141-34163.

4. Guijarro, M.V., Ghivizzani, S.C., and Gibbs CP. (2014) Animal Models in Osteosarcoma. Front Oncol. $4: 189$.

5. Sampson, V.B., Kamata, D.F., and Kolh, E.A. (2013) Xenograft and genetically engineered mouse model systems of osteosarcoma and Ewing's sarcoma: tumor models for cancer drug discovery. Expert Opin. Drug Discov. 8, 1181-1189

6. Ng, A.J.M., Mutsaers A.J., and Wlakley C.R. (2012) Genetically engineered mouse models and human osteosarcoma. Clinical Sarcoma Res. 2, 19.

7. Ordóñez, J.L., Amaral, A.T., Carcaboso, A.M., Herrero-Martín, D., del Carmen GarcíaMacías, M., Sevillano, V., Alonso, D., Pascual-Pasto, G., San-Segundo, L., Vila-Ubach, M., Rodrigues, T., Fraile, S., Teodosio, C., Mayo-Iscar, A., Aracil, M., Galmarini, C.M., 
Tirado, O.M., Mora, J., and de Álava, E. (2015) The PARP inhibitor olaparib enhances the sensitivity of Ewing sarcoma to trabectedin. Oncotarget 6,18875-18890.

8. Stewart, E., Goshorn, R., Bradley, C., Griffiths, L.M., Benavente, C., Twarog, N.R., Miller, G.M., Caufield, W., Freeman, B.B. 3rd, Bahrami, A., Pappo, A., Wu, J., Loh, A., Karlström, Å., Calabrese, C., Gordon, B., Tsurkan, L., Hatfield, M.J., Potter, P.M., Snyder, S.E., Thiagarajan, S., Shirinifard, A., Sablauer, A., Shelat, A.A., and Dyer, M.A. (2014) Targeting the DNA repair pathway in Ewing sarcoma. Cell Rep 9, 829-841.

9. Stewart, E., Federico, S., Karlstrom, A., Shelat, A., Sablauer, A., Pappo, A., and Dyer, M.A. (2016) The Childhood Solid Tumor Network: A new resource for the developmental biology and oncology research communities. Dev. Biol. 411, 287-293.

10. Murakami, T., Igarashi, K., Kawaguchi, K., Kiyuna, T., Zhang, Y., Zhao, M., Hiroshima, Y., Nelson, S.D., Dry, S.M., Li, Y., Yanagawa, J., Russell, T., Federman, N., Singh, A., Elliott, I., Matsuyama, R., Chishima, T., Tanaka, K., Endo, I., Eilber, F.C., and Hoffman, R.M. (2017) Tumour-targeting Salmonella typhimurium A1-R regresses an osteosarcoma in a patient-derived xenograft model resistant to a molecular-targeting drug. Oncotarget 8, 8035-8042. 


\section{Figure Legend}

Figure 1: Schematic illustration of intra-tibial and para-tibial inoculation of cancer cells in mouse.

Figure 2: Histological characteristic of a murine osteoblastic osteosarcoma. (A) Primary bone tumour is characterised by high proliferating tumour cells (white asterix) which produced a mineralized extracellular matrix named osteoid matrix (arrow). (B) After three weeks, metastatic nodules can be easily detected by histological assessment.

Figure 3: Imaging of osteosarcoma model by a two-dimensional X-ray and three-dimensional microcomputed tomography approach. Human MNNG/HOS osteosarcoma cells were inoculated in para-osseous site. Tumour bearing leg and control leg were imaged three weeks after cell inoculation. T: tumour bearing leg; CT: control leg. 


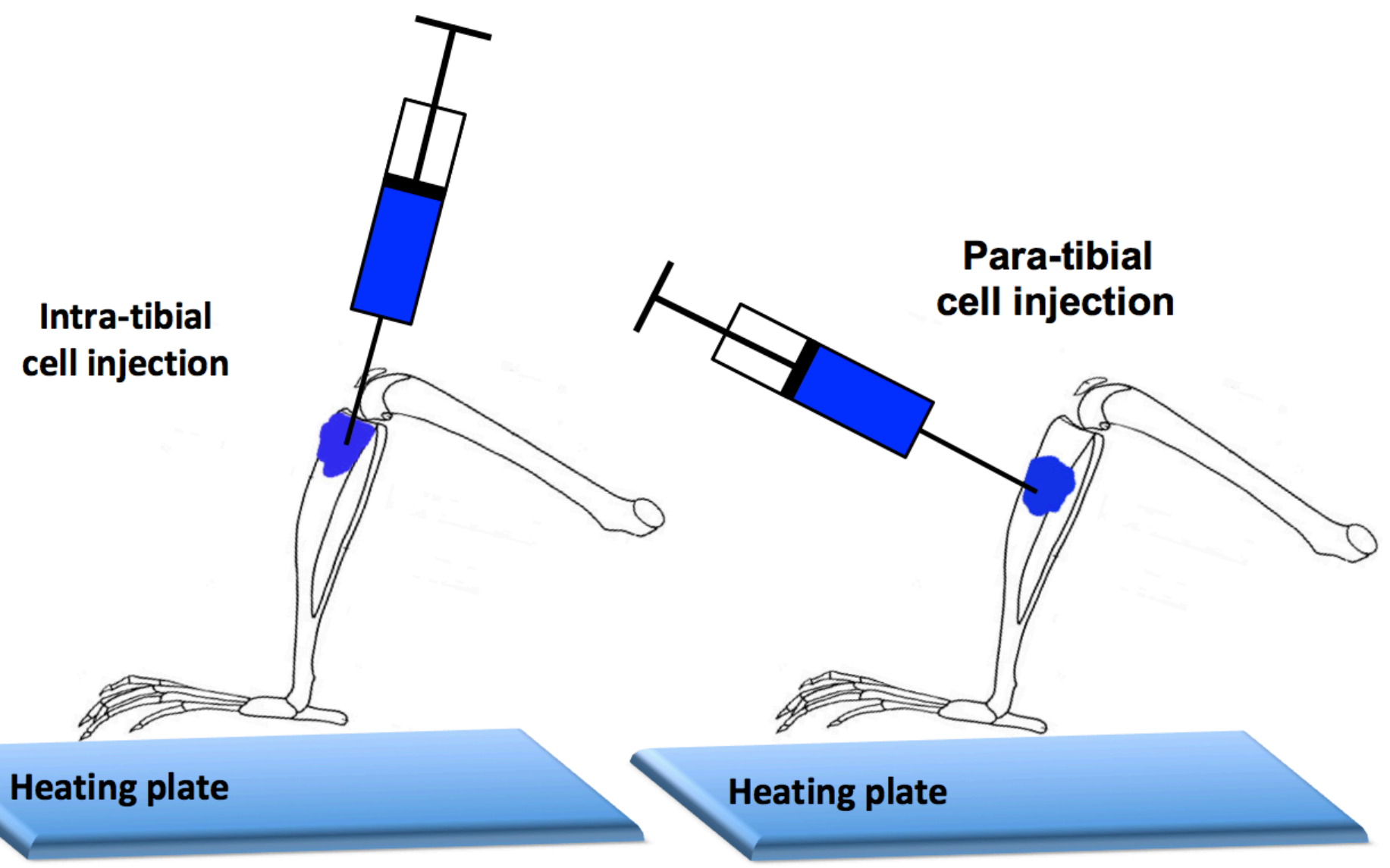




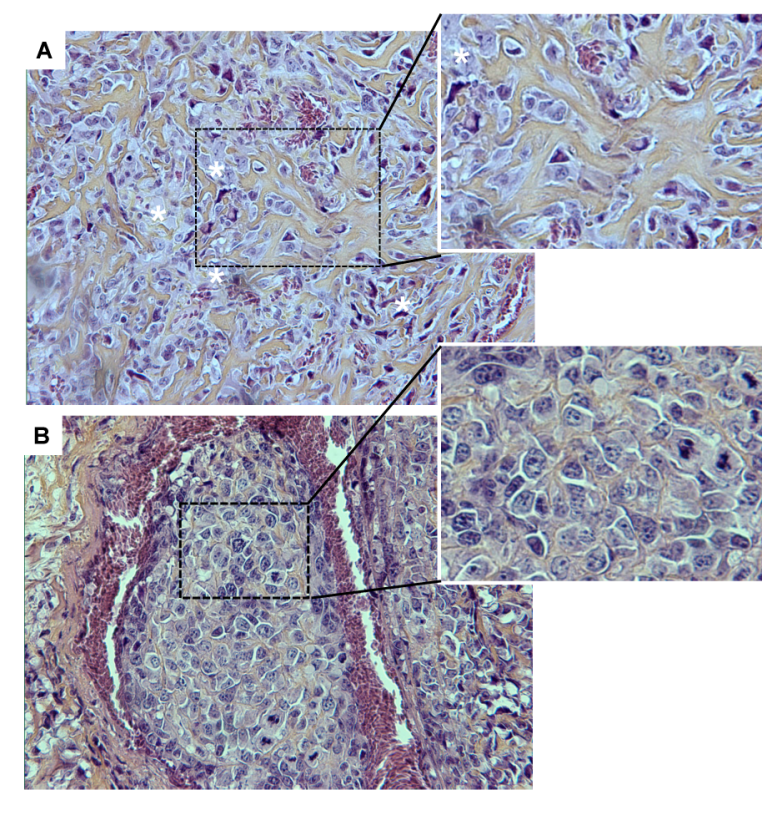




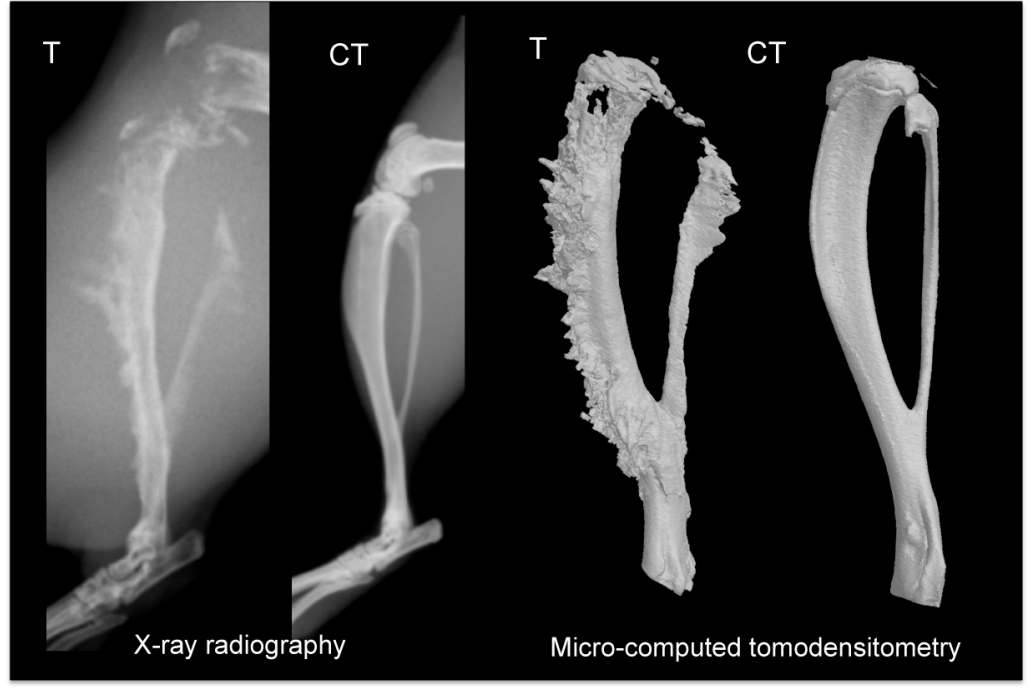


Table 1. Main features of some genetically-engineered murine models of bone sarcomas

\begin{tabular}{|c|c|c|c|c|}
\hline Tumour types & Species & $\begin{array}{c}\begin{array}{c}\text { Genetically engineered } \\
\text { strain }\end{array} \\
\end{array}$ & Genetic feature(s) & $\begin{array}{l}\text { Metastatic } \\
\text { status }\end{array}$ \\
\hline osteosarcoma & mouse & $\begin{array}{l}\mathrm{H}-2 \mathrm{~K}^{\mathrm{b}}-\mathrm{c}-\mathrm{FosLTR} \\
\text { transgenic }\end{array}$ & $\begin{array}{l}\text { Ubiquitous c-Fos } \\
\text { overexpression }\end{array}$ & no \\
\hline osteosarcoma & mouse & OsX-Cre ${ }^{+} R b f / / f l p 53 f / f l$ & $\mathrm{Rb}$ and p53 loss & yes \\
\hline osteosarcoma & mouse & Prx1-Cre $p 53$ lox/lox & $\begin{array}{l}\text { homozygous deletion of } \\
\text { p53 in limb bud } \\
\text { mesenchymal precursors }\end{array}$ & $\begin{array}{l}\text { not } \\
\text { documented }\end{array}$ \\
\hline osteosarcoma & mouse & Prx1-Cre Rb1fl/fl $\operatorname{Trp} 53^{f / / f l}$ & $\begin{array}{l}\text { Homozygous deletion of } \\
\text { p53 and pRb in pluripotent } \\
\text { mesenchymal progenitors }\end{array}$ & $\begin{array}{l}\text { not } \\
\text { documented }\end{array}$ \\
\hline osteosarcoma & mouse & OsX-Cre ${ }^{+} p 53^{f / / f l} p R b^{f / / f l}$ & $\begin{array}{l}\text { p53 and pRb deletion in } \\
\text { osteoblast-progenitors }\end{array}$ & $\begin{array}{l}\text { not } \\
\text { documented }\end{array}$ \\
\hline osteosarcoma & mouse & Apc $1638 N /+;$ Twist $\%$ & $\begin{array}{l}\text { Twist haploinsufficiency } \\
\text { and heterozygosity for } \\
\text { APC1638N }\end{array}$ & $\begin{array}{l}\text { not } \\
\text { documented }\end{array}$ \\
\hline osteosarcoma & mouse & $\begin{array}{l}\text { MOTO mice (OCN } \\
\text { promoter drived SV40 T/t } \\
\text { Antigen) }\end{array}$ & $\begin{array}{l}\text { Prkar1a deletion; RANKL } \\
\text { overexpression }\end{array}$ & yes \\
\hline osteosarcoma & mouse & \begin{tabular}{|l|} 
Osx-Cre+ ${ }^{+}$TRE- \\
shp53.1224
\end{tabular} & $\begin{array}{l}\text { p53 shRNA knock-down in } \\
\text { osteoblast } \\
\text { progenitors/osteoblasts }\end{array}$ & yes \\
\hline osteosarcoma & mouse & Col1a1-Cre Rb1fl/fl $\operatorname{Trp53fl/fl}$ & $\begin{array}{l}\text { Homozygous deletion of } \\
\text { p53 and pRb in pre- } \\
\text { osteoblasts }\end{array}$ & $\begin{array}{l}\text { not } \\
\text { documented }\end{array}$ \\
\hline osteosarcoma & mouse & $O c$-Cre $R b 1^{f l / f l} \operatorname{Trp} 53^{f l / f l}$ & $\begin{array}{l}\text { Homozygous deletion of } \\
\text { p53 and pRb in mature } \\
\text { osteoblasts }\end{array}$ & $\begin{array}{l}\text { Not } \\
\text { documented }\end{array}$ \\
\hline osteosarcoma & mouse & $\begin{array}{l}\text { Osx-Cre }{ }^{+} p 53^{f l / f l} p R b^{f l / f l} \\
\text { Col10a1Tg-Runx2 }\end{array}$ & $\begin{array}{l}\text { p53 and pRb deletion in } \\
\text { osteoblast-progenitors } \\
\text { with RUNX2 genetic } \\
\text { background }\end{array}$ & $\begin{array}{l}\text { not } \\
\text { documented }\end{array}$ \\
\hline osteosarcoma & mouse & HOC-Cre Ptch $11^{f l /+} p 53^{+/-}$ & $\begin{array}{l}\text { upregulation of } \mathrm{Hh} \\
\text { signaling in osteoblasts } \\
\text { and heterozygous deletion } \\
\text { of p53 }\end{array}$ & yes \\
\hline osteosarcoma & mouse & $\begin{array}{l}\text { Col1a1 2.3kb-Cre } \\
\text { Rosa26 }\end{array}$ & $\begin{array}{l}\text { Osteoblast-restricted } \\
\text { expression of NICD-IRES- } \\
\text { GFP (intracellular domain } \\
\text { of Notch1) }\end{array}$ & yes \\
\hline osteosarcoma & rat & $\begin{array}{l}\text { Fisher-F344-Tp53 }{ }^{\text {tm1(EGFP- }} \\
\text { Pac)Qly /Rrrc (F344-Tp53) }\end{array}$ & Tp53 mutant & yes \\
\hline $\begin{array}{l}\text { myeloïd/erythr } \\
\text { oïd leukemia }\end{array}$ & mouse & $\begin{array}{l}\text { Mx1-Cre Rosa26 loxP-stop- } \\
\text { loxP EWS/Fli1 Knock-in }\end{array}$ & $\begin{array}{l}\text { EWS/Fli1 inducible } \\
\text { expression }\end{array}$ & $\begin{array}{l}\text { not } \\
\text { documented }\end{array}$ \\
\hline \begin{tabular}{l|l|} 
Ewing \\
Sarcoma*
\end{tabular} & mouse & Prx1-Cre EWS/Fli1 & EW/Fli1 expression & no \\
\hline $\begin{array}{l}\text { Chondrosacom } \\
\text { a (peripheral) } \\
\text { and } \\
\text { Osteosarcoma }\end{array}$ & mouse & $\begin{array}{l}\text { Col2rtTA-Cr Ext1 } 1^{E 2 f l / E 2 f l} \\
\text { Trp53fl/fl and Col2rtTA-Cre } \\
\text { Ext1 }{ }^{E 2 f l / E 2 f l} \text { Ink4a/Arffl/fl }\end{array}$ & $\begin{array}{l}\text { conditionnal loss of } \\
\text { expression of TP53 or } \\
\text { conditional loss of } \\
\text { expression of Ink4a/Arf }\end{array}$ & $\begin{array}{l}\text { not } \\
\text { documented }\end{array}$ \\
\hline
\end{tabular}

* no tumor formation, developmental defects in the limbs 
Table 2 : Mouse and rat strains used in bone sarcoma models

\begin{tabular}{|l|l|}
\hline \multicolumn{1}{|c|}{ Models } & \multicolumn{1}{c|}{ Mouse strain } \\
\hline Osteosarcoma & BALB/c \\
\hline Murine K7M2 cells & C3H/HeN \\
1 cells & C57BL/6J \\
\hline Murine MOS-J cells & NUDE \\
\hline Murine RF43 & NUDE or SCID \\
\hline $\begin{array}{l}\text { Human osteosarcoma cells } \\
\text { MNNG-HOS, KHOS, 143B, } \\
\text { MG63, U2OS, OHS }\end{array}$ & \\
\hline Chondrosarcoma & NUDE \\
\hline Human SW1353 cells & NUDE \\
\hline Human JJO12 cells & NUDE \\
\hline Ewing sarcoma & $\begin{array}{l}\text { Ewing sarcoma cells (TC71, } \\
\text { A673, SK-NEP-1 }\end{array}$ \\
\hline $\begin{array}{l}\text { Xenografts (Animal or } \\
\text { Patient Derived Xenograft) }\end{array}$ & - NOD/SCID/IL-2RY-null mice \\
\hline \multicolumn{2}{|c|}{ Rat strain } \\
\hline $\begin{array}{l}\text { OSGRA osteosarcoma cells } \\
\text { or tumour fragments }\end{array}$ & Spague Dawley \\
\hline Swarm Chondrosarcoma & Spague Dawley \\
\hline
\end{tabular}

